\title{
The Impact of Parenting Style on Adolescencents' Behavioural Problems in Secondary Schools in Mbooni East Dsub County Makueni County-Kenya
}

\author{
Milcah.W.Mutuku Elizabeth Muema Patricia Makau Grace Igoki Silvia Kainyu \\ Machakos University Department of Educational Psychology
}

\begin{abstract}
This research project was designed to investigate the impact of parenting styles on adolescents' behavioral problems in secondary schools in Mbooni East Sub- district, Makueni County, Kenya. It aimed to establish how parenting styles impacts on adolescents' behavior. The independent variable was parenting style while adolescents' behavioral problem was the dependent variable. The target population was all public secondary schools in Mbooni east sub-district 'Makueni County, Kenya. The study randomly selected eight secondary schools out of the forty- two secondary schools in Mbooni East-sub district. Thirty students were sampled from each school to make a total of two hundred and forty students from form one tolform three. Data was collected and analyzed using SPSS. According to the study findings $66.7 \%$ of the respondents under the authoritarian parenting style, $66.7 \%$ of the respondents' under neglecting parenting style exhibited negative social behavior, while $51 \%$ of the respondents under permissive parenting style exhibited negative social behavior and only $39 \%$ of the authoritative parenting style exhibited negative social behavior. The major recommendation was that authoritative parenting style is a tool for curbing negative social behaviors among schooling adolescents as opposed to the other parenting style.
\end{abstract}

Keywords: An Adolescent, Authoritative parenting style, Authoritarian parenting style, permissive, and uninvolved parenting.

DOI: $10.7176 /$ RHSS/9-2-03

\section{INTRODUCTION}

Parents play a pivotal role in acting as social control and attachment models for their adolescents by providing emotional connection, behavioral constrains and modeling of relationships according to Kincaid (2012). The quality of the parent-adolescent relationship has significant impact on the development or prevention of behavioral problem. When parents provide warmth/support appropriately, monitors behavior, practice discipline and non-coercive ways; adolescents are more likely to develop good behavior. Okorodudu (2010) refers to problem behavior as those which are socially prohibited. These may be any behavior that falls short of societal norms, values, beliefs and expectations. According to Azmiri (2012) these include aggression, truancy, irresponsibility, immorality, alcoholism, vandalism, lies, examination malpractice, sleeping in class, walking out of the teacher, and use of drugs, occultism and others. These behaviors are often established in early childhood and may continue in and intensify through the adolescent period. Okorodudu (2010) further stressed that adolescence is a period of stress and storm. He observed that the period is characterized by rebelliousness caused by non-conducive environment. He found that the foundation of adolescent behavioral problems was rooted in the kind of the home the adolescent was brought up. Collins et al (2010) have noted that there is increased exposure of adolescent to electronic media which has also been reported to have adverse effects on adolescents' behavior. Steinberg (2010) stated that authoritative parenting style provides positive parenting than any other parenting style. Magawi (2004) poor parenting enhances adolescence health problems and increased crime rates. An article in the (Daily Nation, 2010, January $10^{\text {th }}$ ) on what teenagers wished from their parents' argued that most adolescents wished their parents spent more time at home, teaching them basic skills like washing, cooking, etc. Teenagers criticized their parents for turning schools into dumping grounds and leaving the monitory role of their children to teachers. This study was therefore set to find out the impact that exists between parenting styles and behavioral problems among adolescents, since many cases of behavioral problems had been reported among students. It was hoped that the study would set light to school administrators and parents in Mbooni East district Makueni, Kenya.

The study was guided by the following objectives.

i To establish the parenting styles in Mbooni East district.

ii To establish the relationship of uninvolved parenting, authoritarian parenting, permissive parenting and authoritative parenting style and adolescents social behavior.

The study sought to answer the following research questions.

i. What kind of parenting styles existed in the area under study?

ii. How does authoritative, authoritarian, permissive, and uninvolved parenting styles relate with adolescents behavior? 


\section{THEORETICAL FRAMEWORKS}

This study was by guided by Baumrinds theory on parenting styles. Physiologist Baumrind (1991, 1995) identified four patterns of parenting styles based upon two aspects of parenting behavior: control and warmth. Parental control refers to the degree to which parents are accepting and responsive of their children's behavior as opposed to being unresponsive and rejecting. When the two aspects of parenting behavior are combined in different ways four primary parenting styles emerge. These include, authoritative parenting, authoritarians parenting, permissive parents, uninvolved /neglecting parents. Baumrind theory was preferred to guide this study because it explains the relationship between parenting styles and adolescents behavioral problems. Baumrind explains why adolescents fail to be socially adjusted and manifest behavioral problems such as delinquent truancy, drug and substance abuse and social aggression as parental behaviors affect the child from an early age.

\section{METHODOLOGY}

This study was conducted using descriptive survey which sought to establish the current situation in schools. According to Orodho (2003) descriptive survey is method of collecting information by interviewing or administering a questionnaire to a sample of individuals. The study elicited information from students in the schools selected. Questionnaires were used as instruments for data collection. Descriptive survey method was appropriate to collect data from the population since the self-reports helped the researcher obtain attitudes as respondents filled in the questionnaires (Mugenda \& Mugenda, 2003). These would provide a closer approximation of youngsters' true involvement in deviant activity than do official reports such as police records. The study comprised of eight schools; four day mixed schools, one boy school, and two girls' schools.

\section{RESEARCH FINDINGS}

\subsection{Distribution of the Parenting Style}

According to the of study authoritative parenting style had the highest frequency at $83(35 \%)$ followed by permissive parenting style at $79(33 \%)$ and authoritarian parenting style at $48(20 \%)$.Neglecting parenting style had the lowest frequency at 27(11\%).figure1 gives the summary of the finding.

\subsection{Gender Distribution of the Respondents}

Descriptive statistics indicated that out of 237 respondents who participated in

The study, $41.8 \%$ had been filled by male respondents and $58.2 \%$ by female respondents..

The study observed some significant disparity in response with males $99(41.8 \%)$ and females who were more responsive at $138(58.2 \%)$

\subsection{The Respondents Age in Years}

According to the study findings most of the respondents aged between 16 to 18 years with the highest being $69(29.1 \%) 17$ years of age. The least were $4(1.7 \%)$ and $1(0.004 \%)$ aged 14 and 25 years respectively.

\subsection{The Respondents' Residence}

The respondents were asked to state their area of residence.216 (91.1) of the respondents lived in their homes while 21(8.9) of the respondents lived in the market.

It was found that most of the residents $216(91.1 \%)$ resided in their homes while $21(8.9 \%)$ resided in the markets

\subsection{The Persons Staying with the Respondent Most of the Time}

The research sought to find out person the respondents stayed with most of the time. The study noted the person and how he /she related with the respondent.

The study showed that most of the respondents 106 (44.7\%) stayed with their both parents, closely followed by $100(42.2 \%)$ respondents who stayed with their single mothers. The least stayed with their single fathers 5 $(2.1 \%)$

\subsection{The Respondents 'Parents Occupation}

According to the study most of the parents were business persons with $116(48.9 \%)$ and $108(45.6 \%)$ fathers and mothers practicing business respectively. There were more unskilled mothers $55(23.2 \%)$ compared to $26(11 \%)$ unskilled labor fathers. The professional teaching was practiced more by mothers $25(10.5 \%)$ compared to their counterpart fathers at $17(7.2 \%)$. The transport attracted $15(6.3 \%)$ fathers with no mother in the sector from the sampled respondents.

\subsection{Respondents social behaviour}

According to the study findings $124(52.3 \%)$ of the respondents exhibited negative social behavior at public 
secondary schools in Mbooni East district. The study showed that $113(47.7 \%)$ showed a positive social behavior in public secondary schools in Mbooni East district, Makueni County. These findings clearly shows that out of the 237 respondents who successfully filled their questionnaires majority exhibited behavioral problems, a situation that had risen concern in schools in Mbooni East District

\section{8: Social Behaviour and Respondents Gender}

The calculated chi-square value was 4.910 which were greater than the tabulated chi-square value at $5 \%$ significance level with 1 degree of freedom (3.84). Therefore gender was statistically a significant determinant of the adolescents' social behavior at $95 \%$ confidence level since $\chi_{\alpha}^{2}>\chi_{t}^{2}$ and P-value $0.026<0.05$; as shown in table 4.3 proportionally male respondents with negative social behavior had a higher percentage $61.6 \%$ compared to $45.7 \%$ of their counterpart female respondents.. The results of the study findings agree with the researchers who cited that the gender of the parent has great influence on adolescent's behavior.

From these findings it's clear that gender is a significant determinant of adolescents' social behavior, with male respondents exhibiting higher negative social behavior $(61.6 \%)$ than female counter parts who exhibited negative social behaviour $(45.7 \%)$.

\subsection{Social Behaviour and Respondents Living place}

The calculated chi-square value was 0.454 which was less than the tabulated chi-square value at $5 \%$ significance level with 1 degree of freedom (3.84). Therefore the place of residence was statistically not a significant determinant of the adolescents' social behavior at $95 \%$ confidence level since $\chi_{\alpha}^{2}<\chi_{t}^{2}$ and P-value $0.056>0.05$; However proportionally the respondents commuting from home exhibited higher percentage of negative social behavior $113(52.3 \%$ ) compared to $43.7 \%$ of their counterpart respondents reciting at the market.

\subsection{Social behavior and respondent's Fathers Occupation}

The calculated chi-square value was 0.7509 which was less than the tabulated chi-square value at $5 \%$ significance level with 4 degree of freedom (9.488). Therefore the fathers' occupation of the respondents was statistically not a significant determinant of their social behavior at $95 \%$ confidence level since $\chi_{\alpha}^{2}<\chi_{t}^{2}$ and Pvalue $0.940>0.05$; However proportionally the respondents whose fathers worked in the transport sector exhibited higher percentage of negative social behavior 37(82.2\%). The respondents whose fathers were professional teachers and businessmen had the highest positive social behavior in public secondary schools at $37(84.09 \%)$ and $52(88.14 \%)$ respectively.

\subsection{1: Social Behaviour and Respondents Mother's Occupation}

The mothers' occupation was a significant factor in determining the adolescents' social behavior in public secondary schools as opposed to their fathers' occupation. As shown in table 4.6, 76(70.37\%) of the respondents whose mothers were business ladies exhibited negative social behavior in public secondary schools. negatively due to spending less time together. Therefore, having a lower degree of maternal closeness may affect adolescent's behavior. The respondents whose mothers were professional teachers had the highest percentage of positive social behaviour. The calculated chi-square value was 13.65 which were greater than the tabulated chisquare value at $5 \%$ significance level with 3 degree of freedom (7.815). Therefore the mothers' occupation of the respondents was statistically a significant determinant of their social behavior at $95 \%$ confidence level since $\chi_{\alpha}^{2}>\chi_{t}^{2}$ and P-value $0.017<0.05$

4.12: Adolescents' Social Behaviour and Parenting Style

\begin{tabular}{|c|c|c|c|c|c|c|}
\hline \multirow{2}{*}{$\begin{array}{l}\text { Adolescents' } \\
\text { social behavior }\end{array}$} & \multirow[b]{2}{*}{ Count } & \multicolumn{4}{|l|}{ Parenting style } & \multirow[b]{2}{*}{ Total } \\
\hline & & Authoritarian & Neglecting & Authoritative & Permissive & \\
\hline \multirow[t]{2}{*}{0} & Observed & 16 & 9 & 49 & 39 & 113 \\
\hline & Expected & 20.5 & 12.9 & 39.7 & 39.9 & 113 \\
\hline \multirow[t]{2}{*}{1} & Observed & 32 & 18 & 34 & 40 & 124 \\
\hline & Expected & 27.5 & 14.1 & 43.3 & 39.1 & 124 \\
\hline \multicolumn{2}{|l|}{ Total } & 48 & 27 & 83 & 79 & 237 \\
\hline
\end{tabular}

Table 1: Adolescents' Social Behavior and Parenting Style

Source: Researcher (2018

According to the study findings $32(66.7 \%)$ of the respondents under the authoritarian parenting exhibited negative social behavior and $18(66.7 \%)$ of the respondents under the neglecting parenting exhibited negative social behavior also. Generally, the two extreme parenting styles did not appear to be the best in curbing the 
adolescents' vices in secondary schools compared to authorities and permissive parenting style.

The study established that $49(59 \%)$ of the respondents under the authoritative parenting exhibited positive social behavior, and also 39 (49.4) of the respondents under the permissive parenting exhibited positive social behavior. This implies that the best parenting style for positive social behavior among the youth are authoritative and permissive. The calculated chi-square value was 8.199 , which was greater than the tabulated chi-square value at 5\% significance level with 3 degree of freedom indicated that the type of parenting style was statistically significant determinant of adolescents' social behavior at $95 \%$ confidence level since $\chi_{\alpha}^{2}>\chi_{t}^{2}$ and P-value $0.024<0.05$.

\subsection{3: Adolescents' social behavior and the person they live with most of the time}

The calculated chi-square value was 6.626 , which was greater than the tabulated chi-square value at $5 \%$ significance level with 4 degree of freedom (5.99). Therefore the respondents' person they live with most of the time was statistically a significant determinant of adolescents' social behavior at $95 \%$ confidence level since $\chi_{\alpha}^{2}>\chi_{t}^{2}$ and P-value $0.048<0.05$. According to Hadad et, al. (2011) a good relationship with a parent or an adult outside the family can act as a protective factor, making substance abuse and other risky behavior less likely. According to the study findings the level of negative social behavior varied with the person they stayed with most of the time.

Adolescents living father and step mother exhibited the highest percentage of negative social behavior at $72.2 \%$ followed by those who lived with single mothers at 70.8\%.This agrees with Miller (2013) assertion that negative behavior is

\subsection{4: Adolescents' Social Behavior and Their Age in Years}

The respondents' age ranged between 14 to 25 years with the high percentages of negative social behavior occurring between the ages of 16 to 18 years. At this age the adolescence life has fully picked and the highest influence from their peers than their parent is at the peak. The calculated chi-square value was 5.228 which was less than the tabulated chi-square value at 5\% significance level with 7 degree of freedom (14.067). Therefore the respondents' age was statistically not a significant determinant of their social behavior at $95 \%$ confidence level since $\chi_{\alpha}^{2}<\chi_{t}^{2}$ and P-value 0.611>0.05;

\section{5:DISCUSSIONS}

According to the study findings $67 \%$ of the respondents under the authoritarian parenting exhibited negative social behavior and $62 \%$ of the respondents under the neglecting parenting exhibited negative social behavior, while 57\% under permissive parenting also exhibited negative social behavior. These parenting styles did not appear to be the best in curbing the adolescents' vices in secondary schools compared to authoritative parenting style. These study findings agree with D.H sailor (2010) research which stated that children of authoritarian parents are less likely to internalize (accept as their own standards) society's unacceptable norms. Only $33 \%$ of adolescents from authoritative parenting style exhibited negative social behavior. The study also established that $69 \%$ of the respondents under the authoritative parenting exhibited positive social behavior, and $51 \%$ of the respondents under the permissive parenting exhibited positive social behavior. According to the study findings more than two-thirds of the respondents under the authoritarian parenting and two-thirds of the respondents under the neglecting parenting exhibited negative social behavior. This implies that the best parenting style for positive social behavior among the youth is authoritative. These findings agree with Fletcher et, al. (1999) findings that kids raised by authoritative parents are likely to become independent self-reliant, social, successful, and well behaved. They are less likely to report depression and anxiety and less likely to engage in antisocial behavior like delinquency and drugs abuse

\section{6: RECOMMENDATIONS}

Adolescents being the future leaders, guardians and parents, a strong foundation should be made for higher morals and living standards by offering a comprehensive and extensive education without compromising the quality. The highest percentage of respondents with negative social behavior aged between 16 to 18 years who are normally at form two and form three level of study. Therefore the curriculum developers, school administrators and all the education stake holders should allocate more guidance and counseling time to students.

\section{7:. REFERENCES}

Azmiri, S.Vaziri, F.Kashani. (2012). Relationship between maternal and Paternal style and Childs aggressive behaviour. Jounal of Social Behavioral, 69, 1270-81

Bahr,S.J \& Hoffman,J.P.(2010). Parenting style, religiosity, peer and Adolescent heavy drinking: Jounal of Studies on Alcohol and Drugs, 71,539-543. 
Parenting styles on adolescents. Journal of Early Adolescence, 11(1), 53-59.1995)

Baumrind, D. (1991). The influence of parenting style on adolescent Competence and substance use. Journal of Early Adolescence 11(1):56-95

Bednar, D. E \& Fisher, T. D (2003). peer referencing in adolescent decision Making as a function of perceived parenting style. Adolescence.38 (152) 602-21

Brand, S .Hatzinger, M, Beck, J. \& Holsboer-Trachsler, E. (2009). Perceived Parenting styles, personality traits and sleep patterns in adolescents. Journal of Adolescence, 32(5), 1189-1207.

Collins, W. A. Maccoby, E. Steinberg, L. Hetherington, E. M. \&

Bornstein M. H. (2010). Contemporary research on parenting the case for nature and nurture. The American psychologist, 55(2), 218-232.

Eileen, H., Chuansheng C. \& Ellen G. (2011) the role of parenting adult (VIPS) in the lives of older adolescents: Youth and Adolescents 40 (3)310-19.

Fagan ,J. (2011). Paternal and maternal parenting styles and delinquency: Journal of Youth and Adolescence, 40(4) 442-452.

Flecher, Wall,\& Cook B. (2013) contribution of parenting styles in life domain of children. A Journal of Humanities and Social Sciences, 12(2), 91-5.

Fletche. A., Steinberg, L. \& Sellers, E. (1995). Adolescents' wellbeing as a Function of perceived inter-parent inconsistence. Journal of Marriage and Family 61:300-310.

Gwen D. (2010). Parenting styles: A Guide for Science-Minded 11(3) 25-7

Hoeve.M, J., Dubas, S \& Gerris, J., R. (2011). Maternal and paternal Parenting Styles: Unique and Combined Links to Adolescent and Early Adult Delinquency 34(5)813-27.

Hoeve J. Simon \& Eichelsheim, V.(2009). The Relationship between parenting and delinquency: Journal of Abnormal Psychology 37(6)749-77.

Johnson, M.D, \& Galambos,N., L., J. (2014). Paths to intimate relationship quality from parent-adolescent relations and Mental Health: Journal of Marriage and Family, 76,145-160.-90.

Kincaid, C., Jones, D., Sterrett, E. \& McKee, L. (2012). A review of parenting And adolescent sexual behavior: The moderating role of gender. Clinical Psychology Review, 32(3), 177-188. Elsevier Ltd.

Markhon,L. (2012). Relationship between parenting styles and psychopathic traits in children: Behavioral Psychology; 20(3):603-623.

Maccoby \& Martin (1983). Socialization in the context of the family: Parent-child interaction. Handbook of Child Psychology: Vol 4. Socialization, Personality and Social Development (4 ${ }^{\text {th }}$ Ed, pp.1-10) New York: Wiley

Magawi, N., A. (2004). Identifying major behavior problems of adolescent students in secondary schools in Nakuru Municipality Kenya. Unpublished M.ED Thesis, Kenyatta University.

.Mugenda, O., M. \& Mugenda, A., G. (2003). Research methods, qualitative quantitative approaches. Nairobi: African Center for Studies.

Marion, K., Underwood., Baron, J. \& Lisa, H. (2009). Authoritarian and Authoritative styles: A Journal on Aggressive Behavior 35(5)357-375.

Nkoroi, E.M. (2005). A study of behavior problems of adolescents in Secondary schools in Kyeni Division of Embu District. Unpublished M.ed Thesis, Kenyatta University.

Okorodudu, G., N. (2010). Influence of parenting on adolescent's delinquency. Educational Journal of counseling, 3(1).

Otuadah (2006) Influence of parenting style on adolescents: African Journal on Adolescence 32(7).. 